\title{
Cellular Physiology

\section{Expression and Function of Fibroblast Growth Factor (FGF) 7 during Liver Regeneration}

\author{
Su-Mei Tsai ${ }^{1}$ and Wen-Pin Wang ${ }^{1,2}$ \\ ${ }^{1}$ Institute of Medical Sciences, Tzu Chi University, Hualien, ${ }^{2}$ Department of Molecular Biology and Human \\ Genetics, Tzu Chi University, Hualien, Taiwan
}

\section{Key Words}

Fibroblast growth factor 7 (FGF7) - Partial hepatectomy $(\mathrm{PH}) \cdot$ Hydrodynamics - Hepatocyte $•$ Hepatic stellate cell (HSC)

\begin{abstract}
Background/Aim: Previous studies have shown that fibroblast growth factors (FGFs) are involved in the process of liver injury repair. Liver regeneration after partial hepatectomy $(\mathrm{PH})$ is impaired in transgenic mice expressing dominant-negative FGFR2b in hepatocytes. Although FGF7, a ligand specifically bound to FGFR2b, is expressed by activated hepatic stellate cells (HSCs) in fibrotic livers, the expressions and functions of FGF7 and FGFR2b after $\mathrm{PH}$ remain unexplored. Therefore, this study sought to examine the potential role of FGF7 signaling during liver regeneration. Methods: We examined the expression of FGF7 and FGFR2b in normal and regenerating livers. Effects of FGF7 on hepatocytes were examined in vitro using primary hepatocyte culture with FGF7 recombinant protein and in vivo by hydrodynamicbased gene transfer method. Results: We found that FGF7 expression was increased according to the activation status of HSCs after $\mathrm{PH}$. The receptor, FGFR2b, was also increased in hepatocytes during
\end{abstract}

\section{KARGER}

Fax +41613061234

E-Mail karger@karger.ch

www.karger.com
(C) 2011 S. Karger AG, Basel

$1015-8987 / 11 / 0276-0641 \$ 38.00 / 0$

Accessible online at: www.karger.com/cpb liver regeneration. In vitro treatment with FGF7 protein activated ERK1/2 and promoted proliferation of hepatocytes isolated from regenerating livers. In vivo overexpression of exogenous FGF7 could notably promote hepatic proliferation and activate MAPKs after $\mathrm{PH}$. Conclusion: This study suggests a role for activated HSC-expressed FGF7 in stimulating FGF signaling pathways in hepatocytes and regulating liver regeneration.

Copyright @ 2011 S. Karger AG, Basel

\section{Introduction}

The fibroblast growth factor (FGF) family is composed of 22 members, and FGF receptors (FGFR1FGFR4) mediate their biological activities $[1,2]$. Alternative splicing in these receptors' extracellular domain generates additional isoform diversity, providing different ligand-binding specificities. The best understood signaling molecules induced by FGFs are MAPKs, AKT, and PLC $\gamma$ [3]. The signaling pathways of FGF are involved in the developing liver. For example, livers in Fgfr $2 b$ knockout mouse embryos are smaller than those in wild

Wen-Pin Wang

No.701, Section 3, Chung-Yang Road, Hualien (Taiwan 970)

Tel. +886-3-8565301 ext. 2665, Fax +886-3-8578386

E-Mail wpwang@mail.tcu.edu.tw 
type littermates [4]. Several FGFR2b ligands are implicated in developing livers, including FGF1, FGF7, and FGF10. In vitro studies have shown that FGF1 enriches bipotential hepatic progenitor cells, whereas FGF7 promotes differentiation of biliary epithelial cells (BECs) in cultured embryonic livers [5,6]. Expression of FGF10 in hepatic stellate cells (HSCs) is crucial for the developing liver by maintaining survival of hepatoblasts through FGFR2b receptor [4].

Previous studies have identified FGF signaling in both liver repair and regeneration. Expression of FGF1 occurs in both hepatocytes and non-parenchymal cells (NPCs) after partial hepatectomy $(\mathrm{PH})$ [7]. However, $\mathrm{Fgfl} / \mathrm{Fgf} 2$ double knockout mice show normal liver regeneration [8]. Therefore, FGF1 may not have an essential role in liver mass restoration. Increased expression of FGF9 in activated HSCs provides a mitogenic signal to hepatocytes in the liver, which is insulted by $\mathrm{CCl}_{4}$ [9]. Expression of FGF21 is up-regulated in hepatocytes during liver regeneration after $\mathrm{PH}$ or $\mathrm{CCl}_{4}$ administration, but overexpression of FGF21 does not affect compensatory growth after either treatment [10]. The expression level of FGFR4 is abundant in hepatocytes. Although the FGFR4 expression level after PH has not been reported, Fgfr4 knockout mice exhibit normal recovery of liver mass [11]. Therefore, FGFR4 may not be involved in the regeneration process or its function is compensated by other factors. Expression of $F g f r 2$ mRNA increases during liver regeneration [12]. A previous study showed that in addition to FGFR4, hepatocytes also express FGFR2b [13]. Whether or not expression of FGFR2b is increased in hepatocytes after PH is not reported. Because liver regeneration is arrested in the mouse liver expressing dominant-negative FGFR $2 b$ [14], these results demonstrate the importance of FGFR2b signaling in liver regeneration.

Among FGFR2b ligands, FGF7 is a potent mitogen for hepatocytes in vitro that is comparable to the hepatocyte growth factor [15]. In vivo administration of FGF7 protein promotes a small level of hepatocyte proliferation $[16,17]$ and enhances retrovirus infection efficiency without PH [18]. Because FGF7 is expressed by activated HSC in chronic liver diseases of humans [13], and because HSC is activated after PH [19], we hypothesized that FGF7 may participate in the liver regeneration process.

Previous studies have indicated that FGF7 may exert mitogenic effects in hepatocytes during liver injury repair $[13,14,20]$. However, these studies have not provided in vivo evidence to study the role of FGF7 and FGFR2b signaling during liver regeneration. In this study, we analyzed the expressions of FGF7 and FGFR2b in normal and regenerating livers. Furthermore, hepatocytes and other NPCs were isolated from the liver for determining FGF7-expressing cells. Additionally, effects of FGF7 on isolated hepatocytes were analyzed. Because FGF7 is a secreted protein, overexpressing FGF7 by hydrodynamics is feasible to study its effects on hepatocytes after PH. This study shows that FGF7 is expressed in activated HSCs, while FGFR2b is up-regulated in hepatocytes after $\mathrm{PH}$. Additionally, increased activation of FGF7/FGFR2b signaling pathways can promote hepatocyte proliferation during the process of liver regeneration.

\section{Materials and Methods}

Mice

Wild type FVB mice were housed according to protocols approved by the Institutional Animal Care and Use Committee of Tzu Chi University, Hualien, Taiwan.

\section{Partial hepatectomy (PH)}

Male mice at 8-9 weeks old were subjected to $\mathrm{PH}$ under ketamine/xylazine anesthesia $(80-100 \mathrm{mg} / \mathrm{kg})$ by intraperitoneal (i.p.) administration. About $70 \%$ of the liver including the median and left lateral lobes was removed. The remnant liver was analyzed at indicated time points after PH. Greater than $85 \%$ of mice survived after $\mathrm{PH}$ and no significant differences of survival rates were observed in each group.

\section{Isolation of non-parenchymal cells and hepatic stellate} cells

NPCs were prepared by the pronase/collagenase perfusion method [21]. Briefly, after perfusion in situ with $\mathrm{Mg}^{2+}$ and $\mathrm{Ca}^{2+}$-free Hanks balanced salt solution (HBSS), livers were perfused with pronase E (Sigma-Aldrich, St. Louis, MO) and collagenase type IV (Sigma-Aldrich, St. Louis, MO) in HBSS. The perfused liver cells were filtered and centrifuged twice at $50 \mathrm{~g}$ for 2 minutes to remove hepatocytes. The supernatant was further centrifuged at $500 \mathrm{~g}$ for $7 \mathrm{~min}$. The resulting pellet containing NPCs was collected for RNA extraction or resuspended in $8.7 \mathrm{ml}$ of $17.5 \%$ OptiPrep (Sigma-Aldrich, St. Louis, MO), carefully layered on $2.5 \mathrm{ml}$ of $11.5 \%$ OptiPrep and $1 \mathrm{ml}$ of HBSS. Cells were centrifuged at $1400 \mathrm{~g}$ for $17 \mathrm{~min}$ without brakes. Cells at top interface were collected as purified HSCs. The purity of HSCs was greater than $90 \%$ as identified by immunostaining using anti-desmin antibody (DakoCytomation, Glostrup, Denmark).

\section{Isolation of hepatocytes}

Primary hepatocytes were isolated from normal or regenerating livers by 2 -step collagenase perfusion method. Briefly, the liver was perfused with liver perfusion medium (Invitrogen, Carlsbad, CA), followed with liver digest medium 
(Invitrogen, Carlsbad, CA). Hepatocytes were isolated by carefully dissociating the liver with forceps and filtered through a $70 \mu \mathrm{m}$ cell strainer. Hepatocytes were washed twice in cold hepatocyte wash medium (Invitrogen, Carlsbad, CA) by centrifugation at $50 \mathrm{~g}$ for 2 minutes. Viability of the collected hepatocytes assessed by Trypan Blue exclusion exceeded 70\%. Hepatocytes were plated in Williams modified Eagle's medium (Invitrogen, Carlsbad, CA) with 10\% FBS, $1 \mu \mathrm{M}$ insulin, $2 \mathrm{mM}$ glutamine, and $3 \mu \mathrm{M}$ dexamethasone. After adhering hepatocytes for 3 hours, the unattached cells were removed. To determine whether FGF7 could activate ERK1/2 in primary hepatocytes, cells were starved in Williams modified Eagle's medium (Invitrogen, Carlsbad, CA) with $2 \mathrm{mM}$ glutamine, $3 \mu \mathrm{M}$ dexamethason and $1 \mu \mathrm{g} / \mathrm{mL}$ heparin for 48 hours. Subsequently, $50 \mathrm{ng} / \mathrm{ml}$ of FGF7 recombinant protein was added (R\&D Systems, Minneapolis, MN). Cell lysates were harvested at indicated time points after FGF7 treatment.

\section{In vitro proliferation assay}

To determine whether FGF7 can promote proliferation of primary hepatocyte, cells were starved in Williams modified Eagle's medium (Invitrogen, Carlsbad, CA) with $2 \mathrm{mM}$ glutamine, $3 \mu \mathrm{M}$ dexamethason, $1.67 \mu \mathrm{M}$ insulin and $1 \mu \mathrm{g} / \mathrm{mL}$ heparin for 24 hours. Subsequently, $50 \mathrm{ng} / \mathrm{ml}$ of FGF7 recombinant protein was added for another 24 hours (R\&D Systems, Minneapolis, $\mathrm{MN})$. Cultures were incubated with $10 \mu \mathrm{M}$ BrdU for the final 6 hours. Cells were fixed in 4\% paraformaldehyde and used for subsequent staining. Incorporated $\mathrm{BrdU}$ was localized using an anti-BrdU antibody (B2531, 1:100 dilution; Sigma-Aldrich, St. Louis, MO) followed by an HRP-conjugated anti-mouse antibody (1:100 dilution; R\&D Systems, Minneapolis, MN) and a tyramide signal amplification substrate reagent linked with FITC (TSA-FITC) (Perkin Elmer, Waltham, MA). The cells were mounted with SlowFade Gold antifade reagent with DAPI (Invitrogen, Carlsbad, CA).

\section{Immunofluorescence}

Primary NPCs or HSCs perfused from either normal or regenerating livers at indicated time points were seeded on chamber slides. These cells were washed, fixed and permeabilized. Incubation with anti-desmin antibody (M0760, 1:1000 dilution; DakoCytomation, Glostrup, Denmark) at $4^{\circ} \mathrm{C}$ overnight was followed by a HRP-conjugated secondary antimouse antibody (1:100 dilution; R\&D Systems, Minneapolis, MN). TSA-FITC (Perkin Elmer, Waltham, MA) was added as substrate. After blocking the peroxidase activity of secondary antibody, anti-FGF7 antibody (sc-7882, 1:200 dilution; Santa Cruz Biotechnology, Santa Cruz, CA) was added at $4{ }^{\circ} \mathrm{C}$ overnight. HRP-conjugated secondary anti-rabbit antibody (1:100 dilution; R\&D Systems, Minneapolis, MN) and TSATMR substrates (Perkin Elmer, Waltham, MA) were applied. The cells were mounted with SlowFade Gold antifade reagent with DAPI (Invitrogen, Carlsbad, CA).

\section{$R T-P C R$ and quantitative $R T-P C R$}

Total RNA was extracted from liver tissues or isolated primary cells by using TRIZOL reagent (Invitrogen, Carlsbad, CA). Reverse transcribed the RNA by ImpromII RT kit (Promega,

FGF7 Signaling Promotes Liver Regeneration
Madison, WI). For each gene analyzed, an aliquot of cDNA was added to a PCR reaction mixture containing gene-specific primers, including $F g f 7$ sense: 5'-TAC AAG CTT ATG CGC AAA TGG ATA CTG-3' and antisense: 5'-CAT GTC GAC TTA GGT TAT TGC CAT AGG-3'; alpha-smooth muscle actin $(\alpha-$ Sma) sense: 5'-GGC TCT GGG CTC TGT AAG G-3' and antisense: 5'-CTC TTG CTC TGG GCT TCA TC-3'; Fgfr $2 b$ sense: 5'-GCC CAT CCT CCAAGC TG-3' and antisense: 5'-TGG TTG GCC TGC CCT ATA-3'; Fgfr2c sense: 5'-TGA GGA TGC TGG GGA ATA TAC G-3' and antisense: 5'-TAA TCT GGG GAA GCC GTG ATC TCC T-3'; beta2-microglobulin $(\beta 2 m)$ sense: 5'CCG GAG AAT GGG AAG C-3' and antisense: 5'-GTA GAC GGT CTT GGG C-3'. For quantification, Maxima SYBR Green qPCR Master Mix (Fermentas International Inc., Ontario, Canada) was used. Fgf7 sense: 5'-GGC AAT CAA AGG GGT GGA-3' and antisense: 5'-CCT CCG CTG TGT GTC CAT TTA3'; Fgfr $2 b$ and $F g f r 2 c$ primer sequences were the same as RTPCR.

\section{Immunoprecipitation}

Harvested livers or isolated HSCs were lysed in RIPA with protease inhibitor cocktail (Sigma-Aldrich, St. Louis, MO). Total protein concentrations were determined by Bradford protein assay (Bio-Rad, Hercules, CA). Equal amounts of total protein for each sample lysate $(500 \mu \mathrm{g}$ for liver tissues and 250 $\mu \mathrm{g}$ for HSCs) were used. Anti-FGF7 antibody (AF-251-NA, R\&D Systems, Minneapolis, MN) and anti-HA antibody (sc-805, Santa Cruz Biotechnology, Santa Cruz, CA) were used for detecting the expression of endogenous and exogenous FGF7, respectively. Primary antibody was added to the protein lysates at $4{ }^{\circ} \mathrm{C}$ for 2 hours with gentle shake. Protein $\mathrm{G}$ agarose beads (Santa Cruz Biotechnology, Santa Cruz, CA) were then added to the premixed solution and incubated at $4{ }^{\circ} \mathrm{C}$ for 16 hours with gentle shake. Immunoprecipitants were washed for four times with buffer and analyzed by Western blot.

\section{Western blotting}

Anti-FGF7 antibody (AF-251-NA, 1:1000 dilution; R\&D Systems, Minneapolis, MN) was used for detecting FGF7 expression in the livers and HSCs. Antibodies against signaling molecules including ERK1/2 (\#9102), phospho-ERK1/2 (\#9101), P38 (\#9212), phospho-P38 (\#9211), AKT (\#9272) and phosphoAKT (\#9270) were purchased from Cell Signaling Technology (Danvers, MA). Anti-phosphotyrosine 196 FRS2 $\alpha$ antibody (\#3864, 1:500 dilution; Cell Signaling Technology, Danvers, MA) was used to detect the activation of FGF signaling. Anti- $\beta$ actin antibody (MAB1501, 1:5000 dilution; Merck Millipore, Billerica, MA.) was used for the internal control. Goat, mouse or rabbit secondary antibody conjugated with HRP (1:1000 dilution; R\&D Systems, Minneapolis, MN) was applied. The chemiluminescent signals were visualized by Immobilon HRP substrate kit (Millipore, Billerica, MA) and captured by the BioSpectrumAC Imaging System (UVP, Upland, CA). Band intensity was quantified by UVP Visionworks LS software.

\section{Immunohistochemistry}

Five-micrometer thick paraffin-embedded sections were prepared for immunohistochemical staining. Sections were 
Fig. 1. FGF7 expression is increased during liver regeneration. (A) RT-PCR analysis and (B) quantitative RT-PCR analysis of $F g f 7$ mRNA expression in normal ( $\mathrm{PHOh}, \mathrm{n}=14)$ and regenerating livers harvested at PH24h $(n=4)$, PH48h $(n=4)$, $\mathrm{PH} 72 \mathrm{~h}(\mathrm{n}=3)$ and PH120h (n=3). Forty cycles of PCR was used for analyzing $F g f 7$ expression. $\beta 2$ microglobulin $(\beta 2 m)$ was used as an internal control. Data were normalized to $\beta 2 m$ and expressed as fold-induction compared to $\mathrm{PH} 0 \mathrm{~h}$ normal livers (mean $+/-$ SD). ${ }^{*}, \mathrm{P}<0.05$. (C) IP-Western blot analysis of FGF7 protein expression. Normal (PH0h, $\mathrm{n}=22)$ and regenerating livers $(\mathrm{PH} 24 \mathrm{~h}, \mathrm{n}=8 ; \mathrm{PH} 72 \mathrm{~h}$, used as an internal control. (D) The obtained FGF7 protein bands were analyzed and data were expressed as fold-induction compared to $\mathrm{PHOh}$ normal livers (mean $+/-\mathrm{SD}){ }^{*}, \mathrm{P}<0.05$. (E) Desmin and FGF7 double immunofluorescence staining of NPCs isolated from normal and $\mathrm{PH} 72 \mathrm{~h}$ regenerating livers. DAPI was used for nuclear staining. $\mathrm{n}=7$ and PH120h, $\mathrm{n}=7$ ) were harvested. $\beta$-actin was

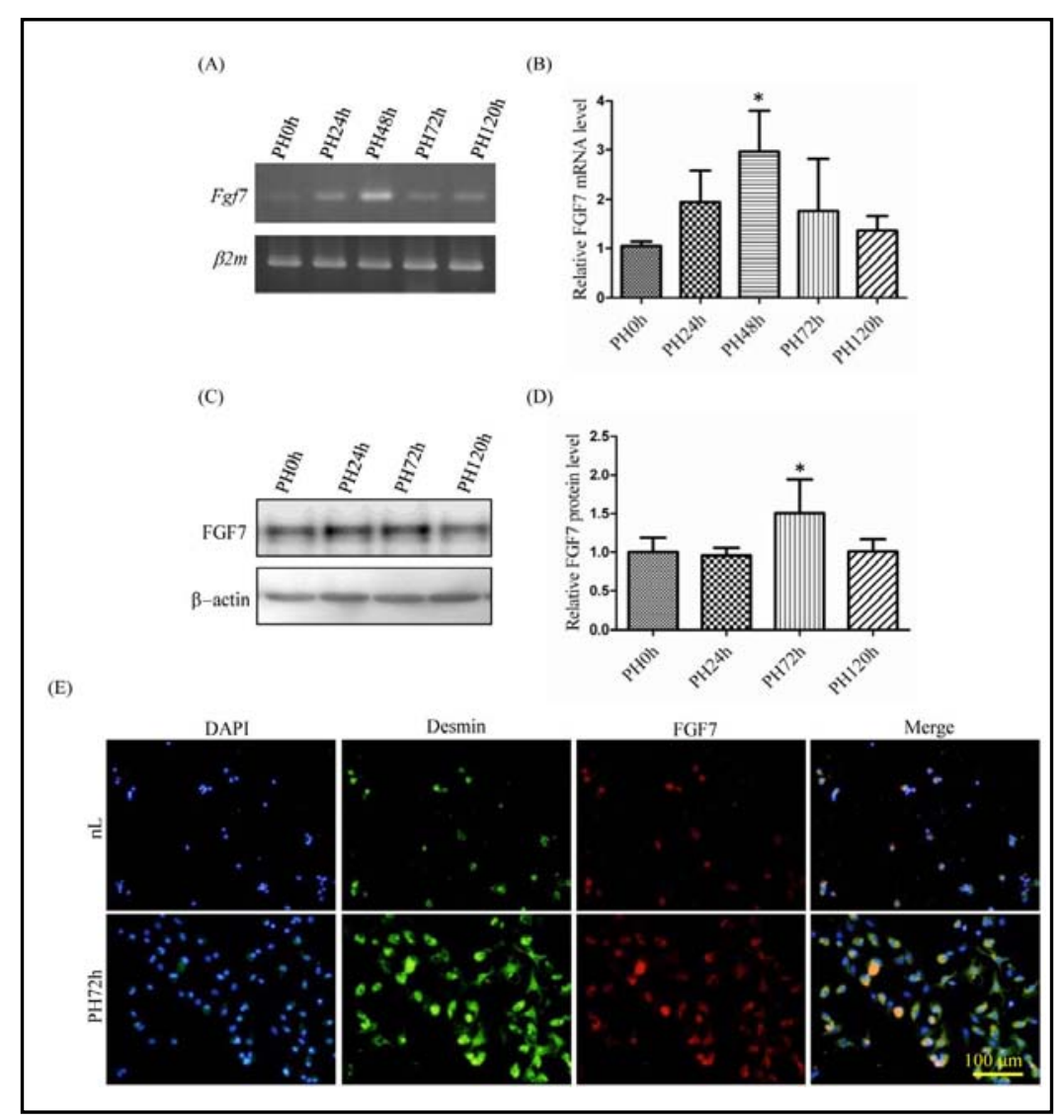

incubated with primary antibody against FGFR2 (sc-122, 1:50 dilution; Santa Cruz Biotechnology, Santa Cruz, CA). Histofine Simple Stain Max PO kit (Nichirei Biosciiences, Tokyo, Japan) was used for detecting FGFR2 signals. For analyzing cells at S phase of cell cycle, mice were i.p. injected with BrdU (GE Healthcare, Buckinghamshire, United Kingdom) 2 hours before being sacrificed. Cell Proliferation kit (GE Healthcare, Buckinghamshire, United Kingdom) was used according to manufacturer's instruction. Anti-PCNA antibody (sc-56, 1:200 dilution; Santa Cruz Biotechnology, Santa Cruz, CA) was also used to detect proliferating cells. After incubation with biotinconjugated anti-mouse antibodies, the positive cells were detected by using Vectastain Elite ABC kit (Vector Labs, Burlingame, CA). Signals were visualized by using DAB substrate kit (Vector Labs, Burlingame, CA). Counterstain was made by hematoxylin. The percentage of hepatic BrdU- or PCNA-positive cells was determined by examination of at least three different random $400 \mathrm{X}$ fields per mouse. At least 3 mice per group at each time point were analyzed. The results were presented as the mean \pm standard deviation (SD). Statistical significance was determined by two-tailed Students $t$ test, with a $P$ value $<0.05$ considered significant.

\section{Hydrodynamics-based gene delivery}

In order to overexpress FGF7 specifically in mouse livers, 7 to 8 weeks old FVB mice were hydrodynamic-injected via tail vein [22]. The control pCG empty plasmid and the pCG-FGF7HA plasmid were used in this study. The pCG-FGF7-HA plasmid encoded FGF7 protein fused with HA-tag was driven by cytomegalovirus (CMV) promoter. Plasmid DNA was prepared by using Endofree plasmid maxiprep kit (Qiagen, Valencia, CA) to minimize contamination of endotoxin. Twenty micrograms of plasmid DNA in $0.9 \% \mathrm{NaCl}$ solution was injected through tail vein smoothly in 5 seconds. For analyzing exogenous FGF7 expression, livers were harvested 1 or 7 days after hydrodynamic injection (H1D or H7D). Mice were subjected to $\mathrm{PH}$ seven days after hydrodynamic injection.

\section{Results}

\section{FGF7 expression in regenerating livers}

Previous studies have shown that FGF7 is a mitogenic growth factor for hepatocytes $[15,18]$. To gain insight into the possible role of FGF7 in liver regeneration, we first analyzed its expression in regenerating livers after PH. Levels of Fgf7 mRNA were detectable in normal livers and increased in regenerating livers as analyzed by RT-PCR (Fig. 1A). Using real-time RT-PCR for quantification, regenerating livers harvested at 48 hours after $\mathrm{PH}$ (PH48h) revealed a 3-fold higher Fgf7 mRNA level than that of normal livers (PHOh) (Fig. 1B). IPWestern blot analyses of FGF7 protein expression in liver lysates prepared from normal and regenerative livers showed a similar result (Fig. 1C). Quantification of the obtained bands revealed a 1.5-fold increase of FGF7 protein at $\mathrm{PH} 72 \mathrm{~h}$ and then decreased to a level 
Fig. 2. Higher level of FGF7 is expressed in activated HSCs after PH. (A) RT-PCR analysis of Fgf7 expression in HSCs isolated from normal $(\mathrm{nL})$ and regenerating livers (PH24h, 72h and 120h). The expression of $\alpha S m a$ was detected for the activated HSCs. $\beta 2 m$ was used as an internal control. (B) Qantitative RT-PCR analysis of $F g f 7$ mRNA expression in HSCs isolated from $\mathrm{nL}$ and $\mathrm{PH} 72 \mathrm{~h}$. Data were normalized to $\beta 2 m$ and expressed as fold-induction compared to normal livers (mean $+/-\mathrm{SD}$ ). *, $\mathrm{P}<0.05$. (C) IP-Western blot analysis of FGF7 protein expression in HSCs isolated from individual mouse livers $(\mathrm{nL}$, PH24h, PH72h and PH120h; $n=3$ for each time point). $\beta$-actin was used as an internal control. (D) The obtained FGF7 protein bands were analyzed and data were expressed as fold-induction compared to normal livers (mean $+/-\mathrm{SD})$. $^{* *}, \mathrm{P}<0.01$. (E) Desmin and FGF7 double immunofluorescence staining of HSCs isolated from PH72h livers. DAPI was used for nuclear staining.

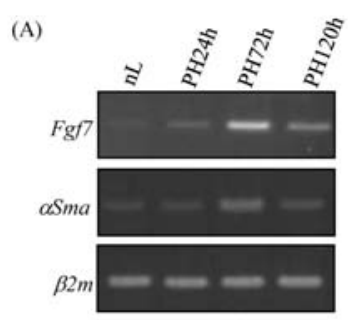

(B)
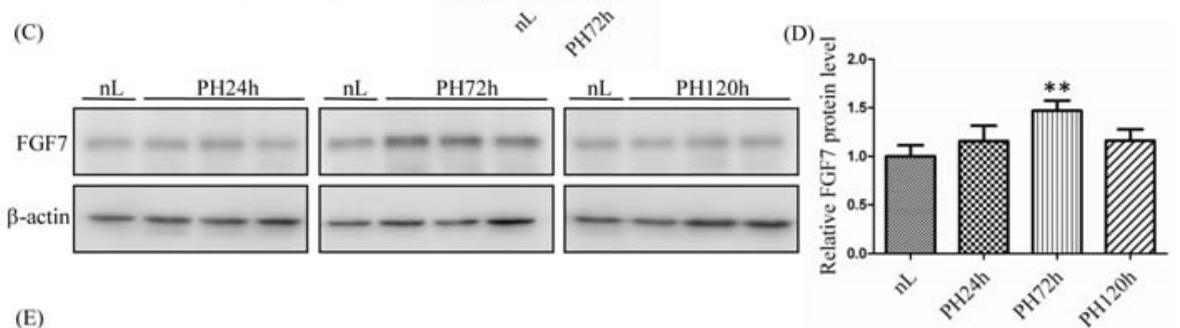

(E)
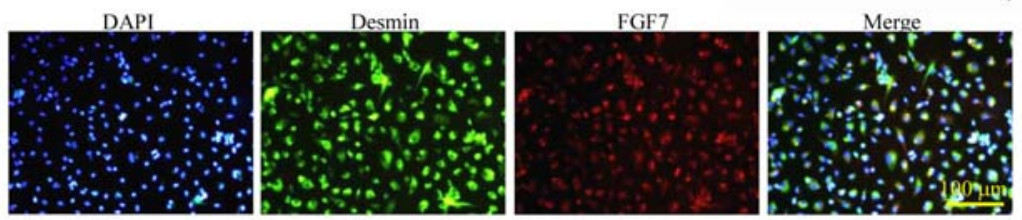

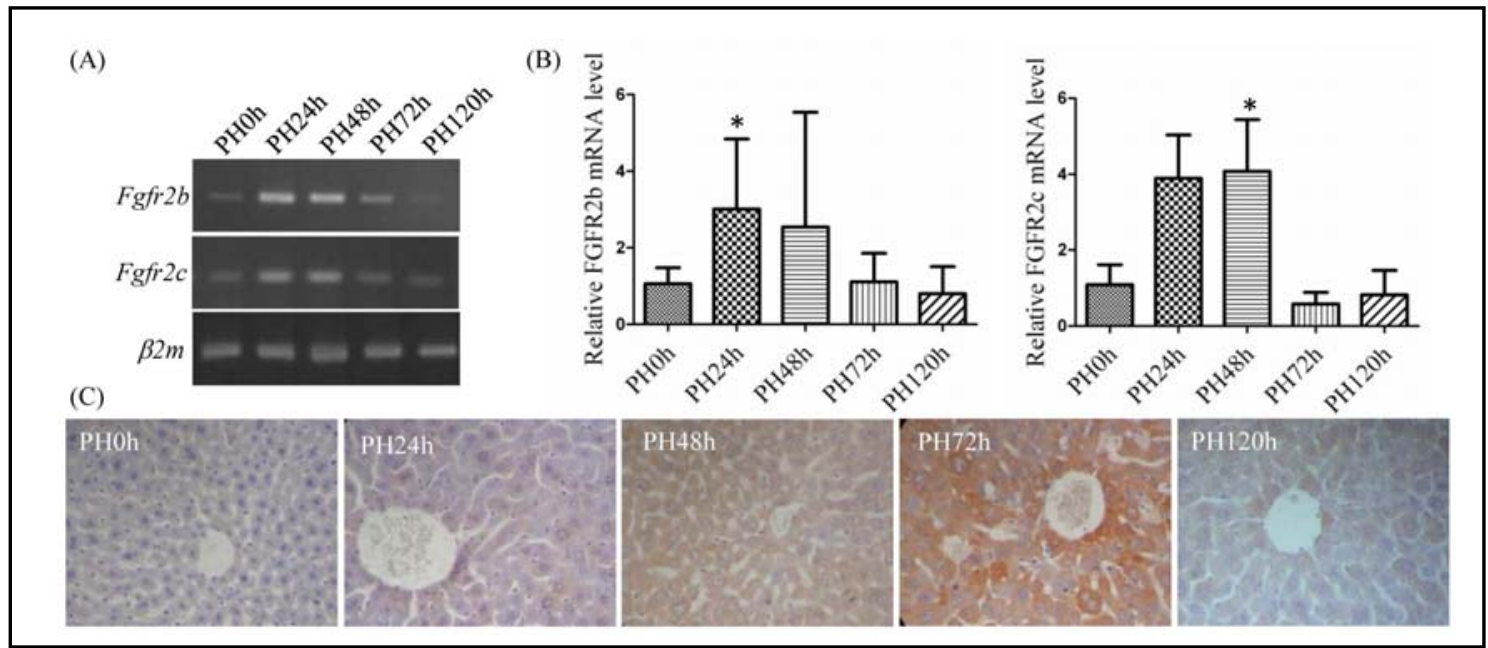

Fig. 3. FGFR2 is increased in the regenerating livers after PH. (A) RT-PCR and (B) quantitative RT-PCR analyses of $F g f r 2 b$ and $F g f r 2 c$ mRNA levels were measured in PHOh normal livers (n=13), and regenerating livers harvested at PH24h (n=7), PH48h $(n=6)$, PH72h $(n=5)$ or PH120h $(n=3)$. mRNA levels were normalized to $\beta 2 m$ and expressed as fold-induction compared to PH0h normal livers (mean $+/-\mathrm{SD}$ ). ${ }^{*}, \mathrm{P}<0.05$. (C) FGFR2 immunostaining of normal liver (PH0h) and regenerating livers (PH24h, PH48h, PH72h, and PH120h). Color was developed using diaminobenzidine as a substrate. Counterstaining was performed with hematoxylin. Original magnifications: 400X.

comparable to normal livers (Fig. 1D). These results indicate that FGF7 may participate in liver regeneration.

Increased FGF7 expression level in activated HSCs after PH

To characterize further and identify the cells responsible for FGF7 expression in the liver, we preliminarily examined the expression of $F g f 7$ mRNA in both isolated hepatocytes and non-parenchymal cells (NPCs). Hepatocytes isolated from normal or $\mathrm{PH} 72 \mathrm{~h}$ regenerating livers did not express Fgf7. By contrast, NPCs isolated from either normal or $\mathrm{PH} 72 \mathrm{~h}$ regenerating livers expressed detectable levels of $\mathrm{Fgf7}$ mRNA (data not shown). These results indicate that NPCs express 
Fig. 4. FGF7 activates downstream FGF signaling and promotes proliferation of primary hepatocytes. Primary hepatocytes from normal $(\mathrm{nL})$ and regenerating livers (PH24h, PH48h, PH72h and PH120h) were serum starved, treated with $50 \mathrm{ng} / \mathrm{ml}$ FGF7, harvested at indicated time points and analyzed for the phosphorylation of (A) FRS $2 \alpha$ and (B) downstream signaling mediators including ERK1/2 and P38. $\beta$-actin was used as an internal control. (C) The ratios of phosphorylated ERK1/2 to total ERK1/2 were analyzed $(n=3$ at each time point) and data were expressed as relative fold-induction of FGF7-stimulated hepatocytes compared to control hepatocytes (mean $+/-\mathrm{SD})$. *, $\mathrm{P}<0.05$ and **, $\mathrm{P}<0.01$. (D) Immunofluorescence of BrdU (green) in hepatocytes isolated from normal $(\mathrm{nL})$ and PH72h livers. Hepatocytes were pulselabeled with BrdU for 6 hours. Cells grown in basal medium without FGF7 were used as controls. (E) Percentages of BrdU-positive hepatic nuclei of FGF7-treated cells were quantified and compared to control cells ( $n=5$ for each group). $* \mathrm{P}<0.05$ and $* * \mathrm{P}<0.01$.

Fig. 5. Exogenous FGF7 is overexpressed in the liver after hydrodynamic injection and PH. FGF7-injected mouse livers were harvested at one day and seven days after injection (H1D and H7D), respectively. PH was performed at $\mathrm{H} 7 \mathrm{D}$ and regenerating FGF7-injected livers were harvested at 6,12 and 24 hours after PH (H/PH6h, 12h and 24h). (A) Quantitative RT-PCR was used to detect the expression of $F g f 7$ mRNA. Data were expressed as relative fold-induction of $\mathrm{Fgf7}$ injected mouse livers compared to $\mathrm{pCG}$ control livers at each indicated time point ( $\mathrm{n}=3$ for each group). ${ }^{*}, \mathrm{P}<0.05$ and ${ }^{* *}, \mathrm{P}<0.01$. (B) Immunoprecipitation was performed with anti-HA antibody and detected with anti-FGF7 antibody by Western blot analysis. $\beta$-actin was used as an internal control.
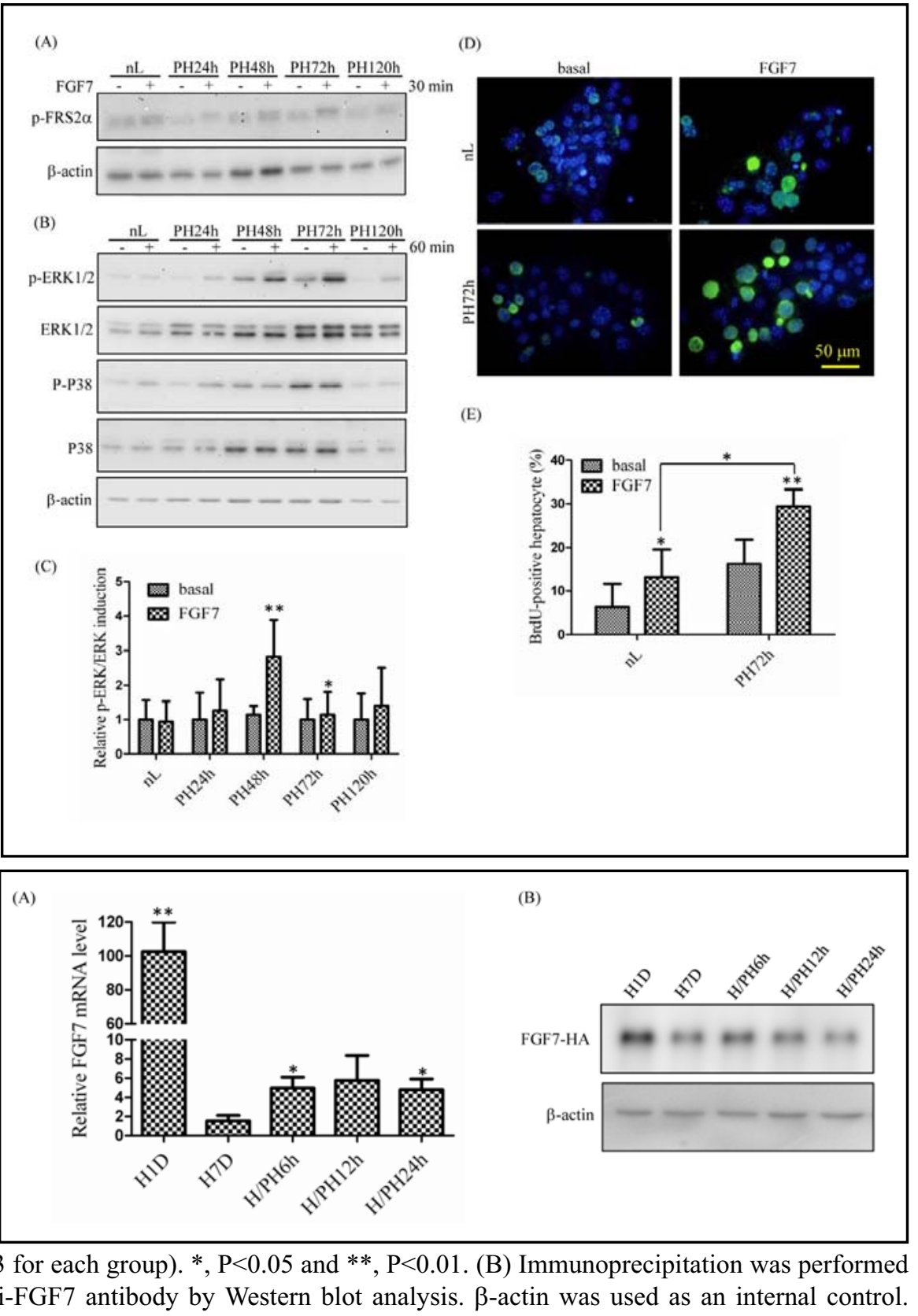

Fgf7. Among NPCs, activated HSCs have been identified as the cellular source of FGF7 in chronic liver disease, such as liver fibrosis [13]. To verify that HSCs also express FGF7 during liver regeneration, immunofluorescence analysis of FGF7 coupled with desmin, a marker of HSCs, was performed in NPCs. We determined that FGF7 was detected only in desmin-positive NPCs from both normal and regenerating livers (Fig. 1E). According to these results, we suggest that FGF7 is produced by HSCs.

Because HSCs are activated not only in fibrotic livers but also in PH-induced regenerating livers $[13,19]$, we sought to determine whether activation of HSC in regenerating liver results in more FGF7 production. Low
Fgf7 mRNA expression was detected in HSCs isolated from normal livers. Levels of $F g f 7$ mRNA in HSCs increased at $\mathrm{PH} 24 \mathrm{~h}$ and peaked at $\mathrm{PH} 72 \mathrm{~h}$. The expression level of $F g f 7$ decreased at PH120h (Fig. 2A). Additionally, the expression of $\alpha \mathrm{Sma}$ in HSCs was paralleled with $\mathrm{Fgf7}$ at each time point examined (Fig. 2A). Real time RT-PCR analysis revealed that $\mathrm{Fgf7}$ expression was 3.3-fold higher in HSCs isolated from $\mathrm{PH} 72 \mathrm{~h}$ regenerating livers compared to those from normal livers (Fig. 2B). These results indicate that the activation of HSCs in regenerating livers may be responsible for the increased expression of $F g f 7$. We further analyzed FGF7 protein expression in isolated HSCs by IP-Western 
Fig. 6. FGF7 overexpression accelerates and increases hepatic BrdU incorporation after PH. Livers were harvested from (A-D) WT mice (PH0h, PH24h, PH48h, and PH72h) or from (E-H) control and (I-L) FGF7-injected mice $(\mathrm{H} / \mathrm{PH} 0 \mathrm{~h}, \mathrm{H} / \mathrm{PH} 24 \mathrm{~h}, \mathrm{H} / \mathrm{PH} 48 \mathrm{~h}$ and $\mathrm{H} / \mathrm{PH} 72 \mathrm{~h}$ ) and stained for BrdU incorporation. Counterstaining was performed with hematoxylin. Scale bar: $100 \mu \mathrm{m}$. (M) Quantified ratios of BrdU-positive hepatic nuclei of pCG control and FGF7-overexpressing livers were compared to that of WT livers ( $n=6$ for each group). A total of 500 nuclei were scored per section at a magnification of $400 \mathrm{X} . * \mathrm{P}<0.05$ and $* * \mathrm{P}<0.01$.

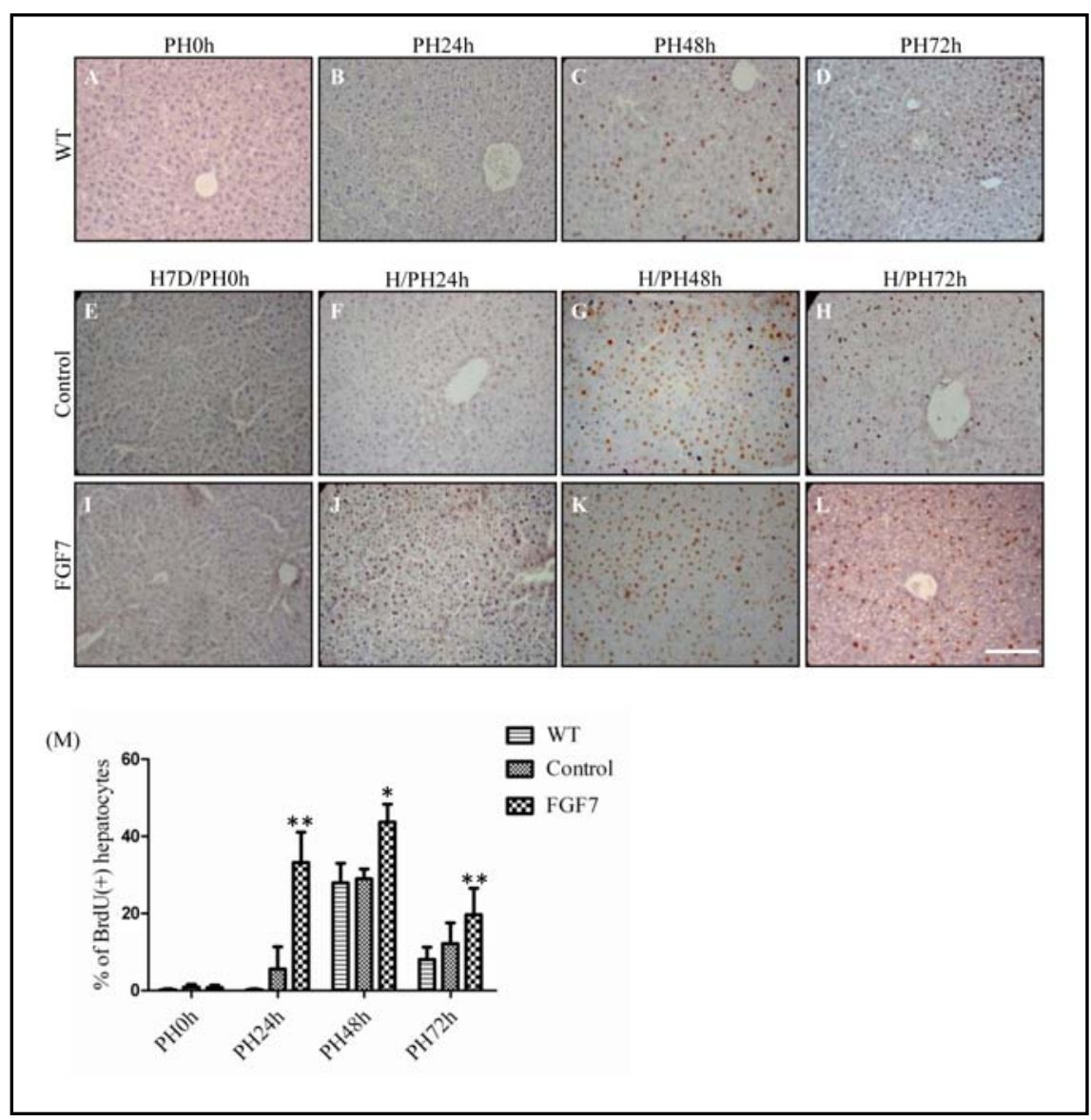

blot analysis. Results showed that FGF7 protein in HSCs isolated from normal livers was low and increased in HSCs isolated from $\mathrm{PH} 72 \mathrm{~h}$ livers (Fig. 2C). Quantification of the obtained bands revealed a 1.5-fold increase of FGF7 protein at $\mathrm{PH} 72 \mathrm{~h}$ and then decreased to a level comparable to normal livers at PH120h (Fig. 2D). Immunofluorescence staining of FGF7 and desmin also showed strong FGF7 signal intensity in HSCs isolated from $\mathrm{PH} 72 \mathrm{~h}$ regenerating livers (Fig. 2E). Therefore, HSCs express FGF7 in normal livers, and activated HSCs produce an increased FGF7 expression during liver regeneration.

\section{FGFR2b expression in normal and regenerating} livers

We next analyzed the hepatic expression of the FGF7 receptor, FGFR2b, during the process of liver regeneration. Levels of $F g f r 2 b$ mRNA were low in normal livers and increased in regenerating livers (Fig. 3A). Using real-time RT-PCR, regenerating livers harvested at $\mathrm{PH} 24 \mathrm{~h}$ revealed a 3 -fold higher Fgfr $2 b$ mRNA level than that of normal livers (PHOh) (Fig. 3B). Immunohistochemical staining revealed that expression of FGFR2 increased gradually after PH. Strong staining of FGFR2 in the hepatocytes was detected especially at
PH72h (Fig. 3C). A decreased FGFR2 signal was observed at PH120h and thereafter (Fig. 3C and data not shown). Because the anti-FGFR2 antibody we used could also detect FGFR2c, a reported FGF receptor expressed in HSCs [9], the expression level of Fgfr2c mRNA during liver regeneration was also examined. Similar to $F g f r 2 b$, the expression of $F g f r 2 c$ increased after $\mathrm{PH}$, and revealed a 4-fold higher expression level at $\mathrm{PH} 48 \mathrm{~h}$ compared to normal livers (PH0h) (Fig. 3A and $3 \mathrm{~B}$ ). These results indicate that both isoforms of FGFR2 increase after PH. Additionally, we suggest the increased level of FGFR $2 b$ in hepatocytes may be crucial for responding to FGF7 in regenerating livers.

Increased activation of FRS $2 \alpha$ and ERK1/2 by FGF7 in hepatocytes from regenerating livers

Previous research has reported that fibroblast growth factor receptor substrate $2 \alpha$ (FRS2 $\alpha$ ) functions as a major mediator downstream from the FGF receptors [23]. To confirm that the increased FGFR2b in hepatocytes can be activated by FGF7 during liver regeneration, phosphorylation of FRS $2 \alpha$ was examined. Hepatocytes were isolated from normal and regenerating livers, serum starved, and treated with FGF7 recombinant protein. We discovered that FGF7 induced the phosphorylation of 
Fig. 7. FGF7 overexpression increases hepatic PCNA expression after PH. Regenerating livers were harvested from (A-C) control and (D-F) FGF7-injected mice (H/PH6h, H/PH12h and $\mathrm{H} / \mathrm{PH} 24 \mathrm{~h}$ ) and stained for PCNA. Counterstaining was performed with hematoxylin. Scale bar: $100 \mu \mathrm{m}$. (G) Quantified ratios of PCNApositive hepatic nuclei in FGF7-overexpressing livers were compared to $\mathrm{pCG}$ control livers $(\mathrm{n}=3$ for each group). A total of 500 nuclei were scored per section at a magnification of $400 \mathrm{X}$. $* * \mathrm{P}<0.01$.

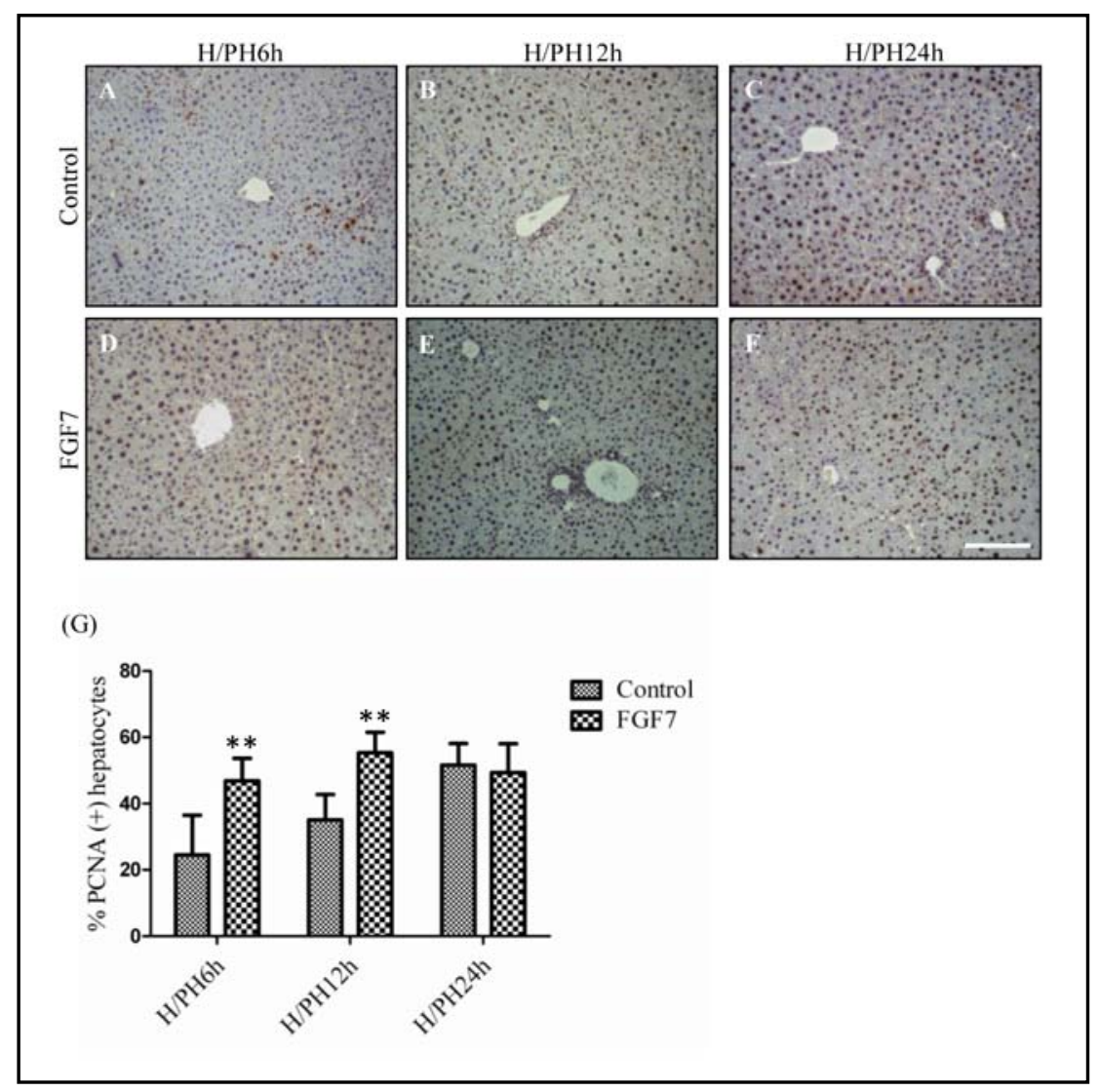

FRS2 $\alpha$ at tyrosine 196 (Fig. 4A), serving as a docking site for direct binding of the GRB2-SOS complex.

We sought to determine whether or not the activity of FGF downstream signaling in hepatocytes from regenerating livers, which express more FGFR2b, is higher after FGF7 treatment. Because the extracellularregulated kinases (ERK1 and ERK2, also known as P44/ P42 MAPKs) are the key effectors in the signal transduction of FGF and ERK1/2 [1] and have also been identified to be crucial for FGF7-induced proliferation in pancreatic cells [24], we analyzed the activation of ERK1/ 2 in hepatocytes after stimulation with FGF7. In hepatocytes isolated from normal livers, activation of ERK1/2 was weak after addition of FGF7 and showed no difference between control cells (Fig. 4B, Lanes 12). Notably, in hepatocytes isolated from livers 24,48 , and 72 hours after $\mathrm{PH}$, activations of ERK1/2 were induced after FGF7 treatment (Fig. 4B, Lanes 3-8). Although activation of ERK1/2 induced after FGF7 treatment in hepatocytes isolated at PH120h (Fig. 4B, Lanes 9-10), the activation level was lower than those observed at $\mathrm{PH} 24 \mathrm{~h}$ to $\mathrm{PH} 72 \mathrm{~h}$. After quantification, we discovered that FGF7 induced a 2.3-fold increase of ERK $1 / 2$ activation levels in hepatocytes isolated from PH48h regenerating livers (Fig. 4C). In addition to ERK1/ 2, slightly increased phosphorylation of P38 by FGF7 was detected at PH24h (Fig. 4B, Lanes 3-4); activations of JNK and AKT were not induced by FGF7 at each time point examined (data not shown). These results indicate that FGF7 activates ERK1/2 downstream from FGF signaling in hepatocytes isolated from regenerating livers.

Increased mitogenic response in primary hepatocytes from regenerating livers

We next studied the effects of FGF7 on DNA synthesis of primary hepatocytes. FGF7 is a mitogenic factor for primary hepatocytes from normal livers of rats [15]. We examined whether or not FGF7 could promote proliferation of primary hepatocytes from regenerating livers. Serum-starved hepatocytes from normal or $\mathrm{PH} 72 \mathrm{~h}$ regenerating livers were stimulated with FGF7 and pulselabeled with BrdU. BrdU-incorporation in primary hepatocytes treated with FGF7 was increased compared to control cells grown in the basal medium (Fig. 4D), suggesting that FGF7 is a mitogen for primary hepatocytes either from normal or regenerating livers. Notably, after FGF7 treatment, the percentage of proliferating hepatocytes from $\mathrm{PH} 72 \mathrm{~h}$ livers was 2.2-fold higher than that of cells from normal livers (Fig. 4E). According to these results, we suggest that increased expression of FGFR $2 b$ during liver regeneration could facilitate FGF7induced proliferation of hepatocytes. 
Fig. 8. FGF7 overexpression activates MAPKs after PH. Livers from $p C G$ control and FGF7-overexpressing livers were collected at 6,12 and 24 hours after $\mathrm{PH}$ (H/PH6h, 12h and 24h). (A) Antibodies against total and phosphorylated ERK1/2 and P38 were used for Western blot analyses. $\beta$-actin was used as an internal control. (B) The ratios of phosphorylated ERK1/2 to total ERK1/2 were analyzed ( $\mathrm{n}=3$ at each time point) and data were expressed as relative fold-induction of FGF7-overexpressed mouse livers compared to $\mathrm{pCG}$ controls (mean +/- SD). *, $\mathrm{P}<0.05$.

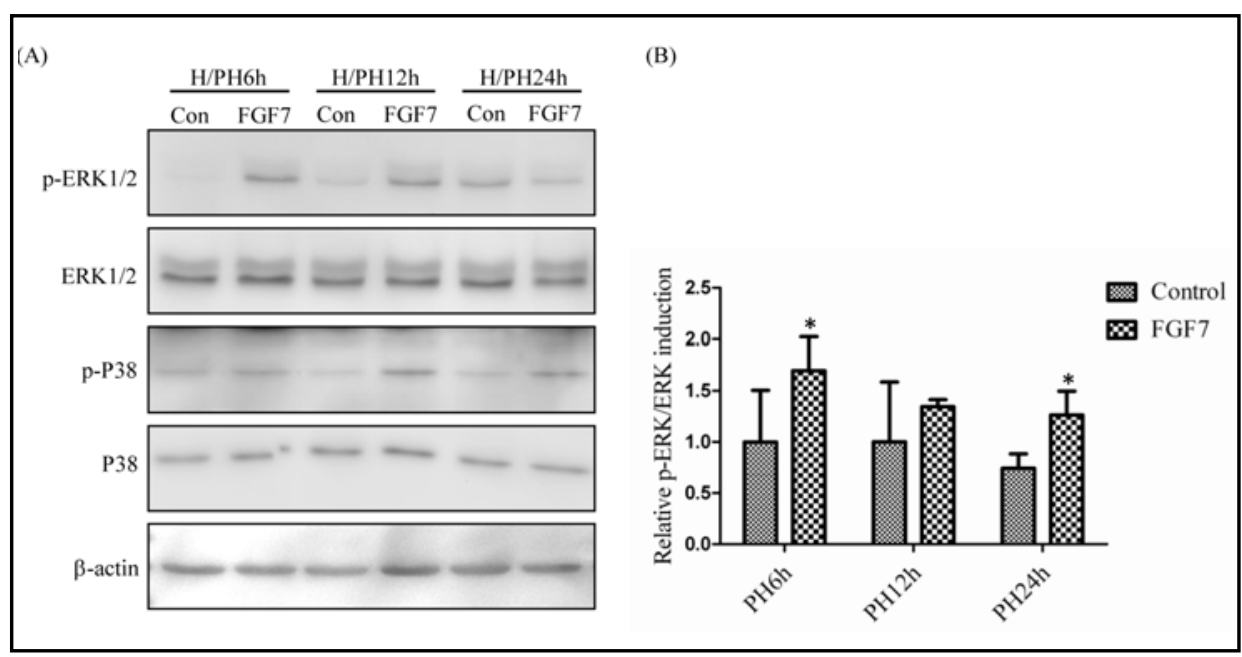

Efficient delivery of FGF7 to the liver by hydrodynamics

To evaluate the role of FGF7 in liver regeneration, we used hydrodynamics to overexpress FGF7 in the liver. This hydrodynamic-based approach can deliver genes efficiently to the liver and has been applied to study liver regeneration $[25,26]$. The control vector (pCG) or FGF7expressing vector (pCG-FGF7-HA) was delivered to the liver and the expression of FGF7 was detected. Real-time RT-PCR showed a high mRNA expression level of Fgf7 one day after hydrodynamic injection (H1D) (Fig. 5A). Liver lysates immunoprecipitated with an anti-HA antibody were detected by Western blot analysis with an anti-FGF7 antibody. Protein of FGF7 was expressed at H1D (Fig. 5B). These results indicate a successful delivery and expression of exogenous FGF7 genes to the liver. Because a previous study showed that hydrodynamic injection causes transient liver injury and then recovers to normal within 1 week [27], PH was performed at 7 days after hydrodynamic injection (H7D). Although the mRNA and protein expression 1 evels of exogenous FGF7 at H7D were not as high as H1D, the expression of exogenous FGF7 was still transiently increased, especially from $\mathrm{PH} 6 \mathrm{~h}$ to $\mathrm{PH} 12 \mathrm{~h}$ (Fig. 5A and 5B). These results show that expression of exogenous FGF7 increases after $\mathrm{PH}$ during liver regeneration.

Advanced DNA synthesis after PH in FGF7overexpressing livers

To determine whether or not overexpressed FGF7 promotes liver regeneration, cell proliferation was analyzed by BrdU incorporation assay. Only few BrdU-positive hepatocytes were detected in wild type (WT) normal livers, control-injected livers, and FGF7-overexpressed livers at
H7D (Fig. 6A, E and I). At PH24h, WT and controlinjected livers exhibited low BrdU-incorporation ratios $(0.16 \pm 0.25 \%$ in WT; $5.55 \pm 5.84 \%$ in control) (Fig. 6B, $\mathrm{F}$ and $\mathrm{M})$. By contrast, a high percentage of BrdU-positive hepatocytes (33.24 $\pm 7.85 \%)$ was detected as early as 24 hours after PH in FGF7-overexpressing livers (Fig. 6J and $6 \mathrm{M})$. In the WT and control mice, BrdU-positive hepatocytes were increased at PH48h (Fig. 6C and 6G). The ratios of BrdU-positive hepatocytes in FGF7overexpressed livers were even greater than those of WT and control livers at this time point (Fig. 6K and 6M). Although all three groups exhibited decreased ratios of BrdU-positive hepatocytes at 72 hours after $\mathrm{PH}$, the ratio was still higher in FGF7-overexpressing livers than in WT and controls (Fig. 6D, H, L, and M). These results suggest that high-level expression of FGF7 can advance the progression of hepatocyte DNA synthesis.

Proliferating cell nuclear antigen (PCNA) has been used as a marker of $\mathrm{G} 0 / \mathrm{G} 1$ transition after $\mathrm{PH}$ [28]. To confirm that the advanced DNA replication in hepatocytes was due to earlier transition of hepatocytes from the quiescent stage into the cell cycle, we examined the expression of PCNA at 6, 12, and 24 hours after PH in control and FGF7-overexpressing livers. The data shows that PCNA-positive hepatocytes increased in FGF7-overexpressed mice at 6 hours $(24.47 \pm 12.04 \%$ in control versus $46.91 \pm 6.7 \%$ in FGF7) and 12 hours after $\mathrm{PH}(35.08 \pm 7.68 \%$ in control versus $55.33 \pm 6.19$ $\%$ in FGF7) (Fig. 7A, B, D, E, and G). Twenty-four hours after $\mathrm{PH}$, both control and FGF7-overexpressed livers exhibited comparable numbers of PCNA-positive hepatocytes (Fig. 7C, F and G). Considered together, these findings indicate that overexpression of FGF7 after $\mathrm{PH}$ can induce cell cycle progression of hepatocytes to promote liver regeneration. 
Activation of MAPKs in FGF7-overexpressing livers after $P H$

From our in vitro study, ERK1/2 and P38 were activated by FGF7 in hepatocytes isolated from regenerating livers (Fig. 4B and 4C). We then analyzed the effects of FGF7 overexpression on MAPKs activation in the regenerating liver after $\mathrm{PH}$. Regenerating livers were harvested from 6 to 24 hours after PH because the expression of exogenous FGF7 was highest during this period and decreased thereafter (Fig. 5). In FGF7-overexpressing livers, the level of ERK1/2 phosphorylation was higher than that of control livers from PH6h to PH12h and decreased at PH24h (Fig. 8A and B). The phosphorylation level of P38 also increased in FGF7-overexpressing livers (Fig. 8A). The activation of AKT was analyzed; however, no difference was apparent in the amount of phosphorylated AKT (data not shown). According to these results, FGF7 might induce hepatocyte proliferation through the MAPK pathways during liver regeneration.

\section{Discussion}

Increased FGF7 and FGFR2b expression during liver regeneration

Inhibition of FGF signals delays liver regeneration in both mice and zebrafish, implying an essential role for this signaling pathway during regeneration $[14,29]$. Initially, we discovered that Fgf7 mRNA expression was upregulated from $24 \mathrm{~h}$ and peaked at $48 \mathrm{~h}$ after $\mathrm{PH}$. This duration corresponded with hepatic proliferation in the mouse PH model [30], suggesting that FGF7 may play a role in the regenerating process. The observation is contrary to the previous finding that $F g f 7$ mRNA is not detected by RNase protection assay (RPA) either in normal livers or in regenerating livers after $\mathrm{PH}[14,31]$. Because sensitivity of RPA (about $10^{5}$ copies of mRNA) is lower than that of RT-PCR (approximately 50 to 100 copies of mRNA) [32], we suggested that although $\mathrm{Fgf7}$ mRNA is increased during liver regeneration, its expression level maybe too low to be detected by RPA. Although increased $F g f 7$ expression in the spleen after $\mathrm{PH}$ might act as an endocrine and reach the liver through the portal circulation [31], our study revealed that PHactivated HSC is another crucial cellular source of FGF7 in regenerating livers.

Consistent with the finding that $F g f r 2$ mRNA expression is increased in regenerating livers after $\mathrm{PH}$ [12], we discovered that the expression of $F g f r 2 b$ is remarkably increased after $\mathrm{PH}$. In vitro study revealed that higher activation levels of FRS $2 \alpha$, ERK1/2, and P38 can be induced after treatment with FGF7 in hepatocytes isolated from regenerating livers. Because FGF7 can specifically bind to FGFR2b [1], which is exclusively expressed by hepatocytes in the liver [13, 31], the activated HSC-produced FGF7 may directly activate FGFR2b on hepatocytes in regenerating livers, implying that an essential paracrine interaction between activated HSCs and hepatocytes may exist during liver regeneration.

\section{Dynamic expression of exogenous FGF7 after} hydrodynamics and $\mathrm{PH}$

To assess the function of FGF7 during liver regeneration, FGF7 was ectopically expressed in hepatocytes by hydrodynamic injection. The FGF7 expression level decreased gradually after hydrodynamic injection. This transgene silencing might be the result of histone modifications that turn episomal vectors into a heterochromatin state [33]. By contrast, another study revealed that histone modification plays no role in gene silencing and the transgene expression is reactivated by a second hydrodynamic injection with saline [34]. Additionally, we discovered transiently increased expression levels of FGF7 after PH. A previous report indicated that histone acetylation precedes DNA replication after $\mathrm{PH}$ [35]. Furthermore, expressions of D-type cyclins and cell cycle progression of hepatocytes after toxic-induced injury require the activity of histone acetyltransferase [36]. Therefore, whether histone acetylation after $\mathrm{PH}$ also contributes to the dynamic expression of transgenes needs to be further examined.

Increased hepatocyte proliferation in FGF7overexpressed livers after $\mathrm{PH}$

Recently, essential cytoprotective effects of FGFR1 and FGFR2 after PH have been reported [31]. A high mortality rate has been observed at $\mathrm{PH} 24 \mathrm{~h}$ in hepatocytespecific $F g f r 1 / F g f r 2$ knockout mice compared to controls. Further examinations have indicated that FGF signaling induces expression of detoxification-related genes immediately after $\mathrm{PH}$, including $D b p$ and Tef. After FGF7 protein is i.p. injected, expression of these two genes is increased in control mice but not in hepatic Fgfrl/Fgfr 2 knockout mice. Therefore, these findings strongly suggest that PH-activated FGF signaling in hepatocytes is crucial for detoxification during liver regeneration. Moreover, hepatocyte proliferation after $\mathrm{PH}$ is normal in $\mathrm{Fg} f \mathrm{r} 4$ knockout mice and is enhanced in the survived hepaticspecific Fgfr 2 knockout mice $[11,31]$. These results are

Tsai/Wang 
different from the inhibition study using the $\mathrm{dn} F g$ fr $2 b$ transgenic mouse model, in which liver regeneration is arrested in the late G1 phase of the cell cycle [14]. In contrast to the above knockout mice, transgenic mouse hepatocytes expressing dnFGFR2b inhibits all FGF signaling. These results indicate that activation of either FGFR2b or FGFR4 alone may be sufficient for normal hepatocyte proliferation.

In this study, we determined that proliferation of hepatocytes after PH was promoted after FGF7 overexpression. Because FGF7 can directly act on primary hepatocytes isolated from regenerating livers to promote their proliferation, the overexpressed FGF7 in vivo might also directly act on hepatocytes to promote proliferation during liver regeneration. However, whether or not FGF7 accelerates hepatocyte proliferation in other indirect manners must still be further examined. We also compared the survival rates after ketamine/xylazine anesthesia and $\mathrm{PH}$ were performed. No obvious difference of survival rate was observed in WT, pCG control or pCG-FGF7-HA-injected mice (data not shown), which might be due to the existence of endogenous FGF signaling cascades. Additionally, we discovered that the recovery of liver mass in FGF7-overexpressed mice after five days of regeneration was comparable to control mice (data not shown). This inconsistency between FGF7 in promoting hepatocyte proliferation and liver mass recovery might be because exogenous FGF7 was only transiently overexpressed in the liver after $\mathrm{PH}$. Therefore, the enhanced mitogenic effect of exogenous FGF7 is correlated with its expression level during liver regeneration.

Activation of MAPKs by exogenous FGF7 in the regenerating livers

Two key effectors activated by FGFs in the signaling pathway are MAPKs and AKT [1, 3]. A previous study showed that ERK1/2 phosphorylation in the midlate $\mathrm{G} 1$ phase after $\mathrm{PH}$ is essential for G1/S phase progression [37]. In this study, we discovered that activations of ERK1/2 and P38 (but not AKT) were induced by FGF7 in hepatocytes isolated from $\mathrm{PH} 48 \mathrm{~h}$ and $\mathrm{PH} 72 \mathrm{~h}$ regenerating livers. When FGF7 was overexpressed in regenerating livers, greater activations of ERK1/2 and P38 were detected, especially from 6 to 12 hours after PH. Recently, FGF7 has been shown to promote proliferation of ductal cells through activating ERK1/2 in diabetic rats with beta-cell deficiency [24]. In hepatic $F g f r l / F g f r 2$ knockout mice, the activations of ERK1/2 and P38 were strongly reduced at PH6h, indicating a defect in the priming phase and subsequent impaired activation of survival-related genes [31]. These findings suggest that FGF7-promoted hepatic proliferation during liver regeneration may be mediated by activating the MAPK signaling pathway.

Our results provide the first evidence for the increased expression of FGF7 and FGFR2b in HSCs and hepatocytes, respectively, during liver regeneration. FGF7 induces phosphorylation of MAPKs but not AKT in vitro or in vivo after PH. In addition to the cytoprotective effects of FGF7 in the priming phase, overexpression of FGF7 in the liver after PH induces hepatocyte proliferation may provide a clue for clinical application of FGF7 protein to promote liver regeneration after surgical resection.

\section{Acknowledgements}

We thank Dr. D. Liu (Department of Pharmaceutical Sciences, University of Pittsburgh, Pittsburgh, USA) and Dr. P.-J. Chen (Graduate Institute of Clinical Medicine, National Taiwan University College of Medicine, Taipei, Taiwan) for advising hydrodynamic injection. We also thank Dr. R. Grose (Center for Tumor Biology, Queen Mary's School of Medicine \& Dentistry, London, UK) for providing us pCG and pCG-FGF7-HA plasmids. The expense of this work was provided by grants from National Science Council (NSC96-2311-B-320-002-MY2) and Tzu Chi University (TCMRC-P-99013-01) to WPW.

\section{References}

\footnotetext{
-1 Eswarakumar VP, Lax I, Schlessinger J: Cellular signaling by fibroblast growth factor receptors. Cytokine Growth Factor Rev 2005;16:139-149.

$\checkmark 2$ Itoh N, Ornitz DM: Functional evolutionary history of the mouse fgf gene family. Dev Dyn 2008;237:18-27.
}

Dailey L, Ambrosetti D, Mansukhani A, 4 Basilico C: Mechanisms underlying differential responses to fgf signaling. Cytokine Growth Factor Rev 2005;16:233-247.
Berg T, Rountree CB, Lee L, Estrada J, Sala FG, Choe A, Veltmaat JM, De Langhe $\mathrm{S}$, Lee R, Tsukamoto H, Crooks GM, Bellusci S, Wang KS: Fibroblast growth factor 10 is critical for liver growth during embryogenesis and controls hepatoblast survival via beta-catenin activation. Hepatology 2007;46:1187-1197. 
-5 Sekhon SS, Tan X, Micsenyi A, Bowen WC, Monga SP: Fibroblast growth factor enriches the embryonic liver cultures for hepatic progenitors. Am J Pathol 2004;164:2229-2240.

Yanai M, Tatsumi N, Hasunuma N, Katsu K, Endo F, Yokouchi Y: Fgf signaling segregates biliary cell-lineage from chick hepatoblasts cooperatively with bmp4 and ecm components in vitro. Dev Dyn 2008;237:1268-1283.

7 Kan M, Huang JS, Mansson PE, Yasumitsu H, Carr B, McKeehan WL: Heparin-binding growth factor type 1 (acidic fibroblast growth factor): A potential biphasic autocrine and paracrine regulator of hepatocyte regeneration. Proc Natl Acad Sci USA 1989;86:7432-7436.

$>8$ Yu C, Wang F, Jin C, Huang X, Miller $>18$ DL, Basilico C, McKeehan WL: Role of fibroblast growth factor type 1 and 2 in carbon tetrachloride-induced hepatic injury and fibrogenesis. Am J Pathol 2003;163:1653-1662.

$\checkmark 9$ Antoine M, Wirz W, Tag CG, Gressner AM, Marvituna M, Wycislo M Hellerbrand C, Kiefer P: Expression and function of fibroblast growth factor (fgf) 9 in hepatic stellate cells and its role in toxic liver injury. Biochem Biophys Res Commun 2007;361:335-341.

10 Huang X, Yu C, Jin C, Yang C, Xie R, Cao D, Wang F, McKeehan WL: Forced $>20$ expression of hepatocyte-specific fibroblast growth factor 21 delays initiation of chemically induced hepatocarcinogenesis. Mol Carcinog 2006;45:934-942.

11 Yu C, Wang F, Kan M, Jin C, Jones RB, 21 Weinstein M, Deng CX, McKeehan WL: Elevated cholesterol metabolism and bile acid synthesis in mice lacking membrane tyrosine kinase receptor fgfr4. J Biol Chem 2000;275:15482-15489.

$12 \mathrm{Hu}$ Z, Evarts RP, Fujio K, Marsden ER, Thorgeirsson SS: Expression of fibroblast growth factor receptors flg and bek during hepatic ontogenesis and regeneration in the rat. Cell Growth Differ 1995;6:1019 1025 .

13 Steiling H, Muhlbauer M, Bataille F, Scholmerich J, Werner S, Hellerbrand C: Activated hepatic stellate cells express keratinocyte growth factor in chronic liver disease. Am J Pathol 2004;165:1233-1241.

14 Steiling $\mathrm{H}$, Wustefeld $\mathrm{T}$, Bugnon $\mathrm{P}, \longrightarrow 25$ Brauchle M, Fassler R, Teupser D, Thiery J, Gordon JI, Trautwein C, Werner S: Fibroblast growth factor receptor signalling is crucial for liver homeostasis and regeneration. Oncogene 26 $2003 ; 22: 4380-4388$
Itoh T, Suzuki M, Mitsui Y: Keratinocyte growth factor as a mitogen for primary culture of rat hepatocytes. Biochem Biophys Res Commun 1993;192:10111015.

Housley RM, Morris CF, Boyle W, Ring B, Biltz R, Tarpley JE, Aukerman SL, Devine PL, Whitehead RH, Pierce GF: Keratinocyte growth factor induces proliferation of hepatocytes and epithelial cells throughout the rat gastrointestinal tract. J Clin Invest 1994;94:1764-1777.

17 Strain AJ, McGuinness G, Rubin JS, Aaronson SA: Keratinocyte growth factor and fibroblast growth factor action on DNA synthesis in rat and human hepatocytes: Modulation by heparin. Exp Cell Res 1994;210:253-259.

Bosch A, McCray PB Jr, Chang SM, Ulich TR, Simonet WS, Jolly DJ, Davidson BL: Proliferation induced by keratinocyte growth factor enhances in vivo retroviral-mediated gene transfer to mouse hepatocytes. J Clin Invest 1996;98:2683-2687.

Asai K, Tamakawa S, Yamamoto M, Yoshie M, Tokusashi Y, Yaginuma Y, Kasai S, Ogawa K: Activated hepatic stellate cells overexpress p75ntr afte partial hepatectomy and undergo apoptosis on nerve growth factor stimulation. Liver Int 2006;26:595-603. Senaldi G, Shaklee CL, Simon B, Rowan CG, Lacey DL, Hartung T: Keratinocyte growth factor protects murine hepatocytes from tumor necrosis factorinduced apoptosis in vivo and in vitro. Hepatology 1998;27:1584-1591.

Passino MA, Adams RA, Sikorski SL, Akassoglou K: Regulation of hepatic stellate cell differentiation by the neurotrophin receptor p75ntr. Science 2007;315:1853-1856.

22 Liu F, Song Y, Liu D: Hydrodynamicsbased transfection in animals by systemic administration of plasmid DNA. Gene Ther 1999;6:1258-1266.

23 Gotoh N: Regulation of growth factor $>36$ signaling by frs 2 family docking/scaffold adaptor proteins. Cancer Sci 2008;99:1319-1325.

24 Uzan B, Figeac F, Portha B, Movassat J: Mechanisms of kgf mediated signaling in pancreatic duct cell proliferation and $>37$ differentiation. PLoS One 2009; 4:e4734.

Li W, Zhu H, Bao W, Fu H, Li Z, Liu X, $\mathrm{Xu} \mathrm{R}$, Zhao J, Zhang Y: Involvement of metastasis tumor antigen 1 in hepatic regeneration and proliferation. Cell Physiol Biochem 2008;22:315-326.

Nejak-Bowen KN, Thompson MD, Singh S, Bowen WC Jr, Dar MJ, Khillan J, Dai C, Monga SP: Accelerated liver regeneration and hepatocarcinogenesis in mice overexpressing serine-45 mutant betacatenin. Hepatology 2010;51:16031613.
Rossmanith W, Chabicovsky M, Herkner $\mathrm{K}$, Schulte-Hermann R: Cellular gene dose and kinetics of gene expression in mouse livers transfected by high-volume tailvein injection of naked DNA. DNA Cell Biol 2002;21:847-853.

Koch KS, Maeda S, He G, Karin M, Leffert HL: Targeted deletion of hepatocyte ikkbeta confers growth advantages. Biochem Biophys Res Commun 2009;380:349-354.

-29 Kan NG, Junghans D, Izpisua Belmonte JC: Compensatory growth mechanisms regulated by bmp and fgf signaling mediate liver regeneration in zebrafish after partial hepatectomy. FASEB J 2009;23:3516-3525.

Weglarz TC, Sandgren EP: Timing of hepatocyte entry into DNA synthesis after partial hepatectomy is cell autonomous. Proc Natl Acad Sci USA 2000;97:12595-12600.

Bohm F, Speicher T, Hellerbrand C, Dickson C, Partanen JM, Ornitz DM, Werner S: Fgf receptors 1 and 2 control chemically induced injury and compound detoxification in regenerating livers of mice. Gastroenterology 2010;139:13851396.

Rottman JB: The ribonuclease protection assay: A powerful tool for the veterinary pathologist. Vet Pathol 2002;39:2-9.

Riu E, Chen ZY, Xu H, He CY, Kay MA: Histone modifications are associated with the persistence or silencing of vectormediated transgene expression in vivo. Mol Ther 2007;15:1348-1355.

Ochiai H, Fujimuro M, Yokosawa H, Harashima H, Kamiya $\mathrm{H}$ : Transient activation of transgene expression by hydrodynamics-based injection may cause rapid decrease in plasmid DNA expression. Gene Ther 2007;14:11521159

Weiss G, Puschendorf B: The maximum of the histone acetyltransferase activity precedes DNA-synthesis in regenerating rat liver. FEBS Lett 1988;238:205-210. Shukla V, Cuenin C, Dubey N, Herceg Z: Loss of histone acetyltransferase cofactor transformation/transcription domain-associated protein impairs liver regeneration after toxic injury. Hepatology 2011;53:954-963.

Talarmin H, Rescan C, Cariou S, Glaise D, Zanninelli G, Bilodeau M, Loyer P, Guguen-Guillouzo C, Baffet G: The mitogen-activated protein kinase kinase/ extracellular signal-regulated kinase cascade activation is a key signalling pathway involved in the regulation of $\mathrm{g}(1)$ phase progression in proliferating hepatocytes. Mol Cell Biol 1999;19:6003-6011. 